\title{
Treatment of retinal pigment epithelial detachment with antiangiogenic therapy
}

This article was published in the following Dove Press journal:

Clinical Ophthalmology

14 April 2010

Number of times this article has been viewed

\section{Luis Arias \\ Department of Ophthalmology, Bellvitge University Hospital, Barcelona, Spain}

Correspondence: Luis Arias Department of Ophthalmology, Bellvitge University Hospital, C/Feixa Llarga, S/N, L'Hospitalet de Llobregat, 08907, Barcelona, Spain

Tel +34 932607600

Fax +34 9| 4909749

Email luisarias@telefonica.net
Purpose: Evaluate the efficacy of pegaptanib, a selective anti-vascular endothelial growth factor (VEGF) agent, and bevacizumab, a nonselective anti-VEGF agent, for retinal pigment epithelial detachment (PED) associated with occult choroidal neovascularization (CNV) secondary to age-related macular degeneration (AMD).

Methods: Prospective, comparative, nonrandomized pilot study included patients with PED comprising $>50 \%$ of total lesion in subfoveal location with visual acuity (VA) 20/40-20/400 and lesions either previously untreated or treated only with photodynamic therapy/verteporfin. Seven patients received pegaptanib $0.3 \mathrm{mg}$ intravitreally (IVT); eight received IVT bevacizumab $1.25 \mathrm{mg}$. Follow-up occurred every 4-6 weeks for 6 months. Reinjection of initial medication occurred if there was intra- or subretinal fluid observed by optical coherence tomography (OCT) or increased PED. Endpoints were mean changes from baseline to month 6 in VA (ETDRS) and foveal thickness.

Results: At baseline, mean VA was lower, and mean foveal thickness was greater in pegaptanib versus bevacizumab-treated patients (36.1 vs 49.5 letters; 470.4 vs $321.1 \mu \mathrm{m}$ ). Mean improvements to month 6 in VA and foveal thickness were greater for pegaptanib (VA: +9.1 vs +7.2 letters; foveal thickness: $-88.2 \mathrm{vs}-52.9 \mu \mathrm{m})$. On average, pegaptanib-treated patients had slower but more sustained improvement in VA and foveal thickness; bevacizumab-treated patients showed rapid improvement with a slow return towards baseline. Both agents were well tolerated.

Conclusion: Intravitreal injections of pegaptanib or bevacizumab are both efficacious and safe treatments for PED associated with occult CNV secondary to AMD.

Keywords: bevacizumab, pegaptanib, retinal pigment epithelial detachment

\section{Introduction}

Retinal pigment epithelial detachment (PED), in which the retinal pigment epithelium (RPE) physically separates from the underlying Bruch's membrane, occurs in association with many diseases of the retina, the most common being age-related macular degeneration (AMD). ${ }^{1}$ In patients with AMD, PEDs are classified by clinical appearance and angiographic characteristics as confluent drusen, serous, turbid, hemorrhagic, vascular or fibrovascular, and fibrous or organized. ${ }^{2-5}$ The underlying pathophysiology of PED is complex and not clearly understood. Several contributing mechanisms have been proposed, the most obvious being displacement of the RPE by exudation from choroidal neovascularization (CNV). Because CNV is not always identified in patients with PED, however, controversy exists as to whether CNV develops as a complication of existing $\mathrm{PED}^{6}$ or whether the growth of CNV vessels through Bruch's membrane directly causes PED. ${ }^{5}$ Bird and Marshall ${ }^{7}$ suggested that PED results when Bruch's 
membrane is thickened from the progressive accumulation of lipid or lipoprotein deposits, leading to increased hydrophobic resistance to the normal active transport of fluid and resulting in fluid accumulation beneath the RPE. These hypotheses concerning the pathogenesis of PED are believed not to be mutually exclusive. ${ }^{8}$

The visual prognosis for patients with CNV-associated PED may be especially poor. In a study that followed 55 eyes of 53 patients for an average of 2.2 years, $62 \%$ of patients were reported to have lost 6 or more lines of vision, with $75 \%$ having a final visual acuity of 20/200 or worse. ${ }^{9}$ Elman et a ${ }^{10}$ reported in a retrospective analysis of the natural history of PED in patients without $\mathrm{CNV}$ that $52 \%$ of patients maintained an initial visual acuity of 20/20-20/40 through an average of 32.8 months. ${ }^{10}$ Another study involving 101 eyes reported a similar course of vision loss irrespective of PED type. ${ }^{11}$ Although patients without CNV may have a better prognosis at the onset, they are at high risk of developing CNV and subsequent vision loss. In the Elman et al study, ${ }^{10} 32 \%$ of patients eventually developed CNV while in another series, ${ }^{12} 67 \%$ of patients with serous PED developed CNV after a maximum of 19 months. Since serous PED may obscure the extent of any existent $\mathrm{CNV}$, it should be noted that proper assessment of patients with sub-RPE fluid is often rendered difficult. ${ }^{1}$

The management of AMD patients with PED is controversial due to the difficulty in determining the presence of associated CNV and the inability to reliably identify those patients with serous PED who are likely to develop CNV and experience severe vision loss. In addition, treatment options for PED are limited and usually of poor outcome. While one trial ${ }^{13}$ of angiographically directed laser photocoagulation involving 35 eyes reported stabilization or improvement of vision in $60 \%$, other attempts ${ }^{14,15}$ with both unguided and guided photocoagulation reported much inferior results, with treated eyes faring worse than untreated controls. Results of studies of photodynamic therapy (PDT) with verteporfin have also not been encouraging. Although patients with PED were not specifically studied in either the Treatment of Age-related Macular Degeneration with Photodynamic Therapy (TAP) or Verteporfin in Photodynamic Therapy (VIP) trials, ${ }^{16,17}$ a recent study ${ }^{18}$ enrolling lesions of $<2$ months' duration found that $60 \%$ of patients had improved or stabilized vision over a 16-month follow-up. In contrast, other groups ${ }^{19,20}$ have reported that PDT with verteporfin conferred little treatment benefit, even when combined with intravitreal triamcinolone acetonide. ${ }^{21}$ In these trials, treatment was also complicated by subretinal hemorrhage and RPE tears.
Based on the suboptimal treatment outcomes with laser and PDT with verteporfin there is a need for a therapeutic approach that improves the prognosis of PED secondary to AMD. One promising avenue involves agents that inactivate vascular endothelial growth factor (VEGF), the most potent known promoter of angiogenesis ${ }^{22}$ and vascular permeability ${ }^{23}$ both of which appear to play a role in the pathogenesis of PED. Two intravitreal VEGF antagonists indicated for the treatment of all angiographic subclasses of CNV are commercially available: pegaptanib, an RNA aptamer, which has high affinity and specificity for the 165 amino acid isoform of VEGF while sparing VEGF $_{121},{ }^{24,25}$ and ranibizumab, an Fab antibody fragment that inactivates all VEGF isoforms. ${ }^{26-28}$ In addition, bevacizumab, an antibody related to ranibizumab, which is indicated for intravenous treatment of cancer in combination with chemotherapeutic agents (see prescribing information at: http://www. gene.com/gene/products/information/oncology/avastin/ insert. jsp\# indications) and which also inactivates all VEGF isoforms, has been used in off-label studies to treat neovascular AMD. ${ }^{29}$ The present pilot study examined the effectiveness of pegaptanib and bevacizumab in the treatment of PED associated with occult CNV secondary to AMD. The results are encouraging and merit further study in an appropriately designed randomized clinical trial.

\section{Methods}

This prospective, comparative, nonrandomized pilot study included patients with PED comprising $>50 \%$ of the total lesion in the subfoveal location. Eligible patients had visual acuity between 20/40 and 20/400, and lesions that either had not been treated previously or had been treated only with PDT with verteporfin. Visual acuity (Early Treatment Diabetic Retinopathy Study [ETDRS]), a complete ophthalmic examination, indocyanine green angiography, fluorescein angiography, and optical coherence tomography (OCT) were evaluated at baseline. Examinations were completed 5-7 days before the administration of the first intravitreal injection.

The first seven patients presenting with PED received intravitreal injections of commercially available pegaptanib sodium 0.3 mg (Macugen ${ }^{\circledR}$; [OSI] Eyetech, Inc and Pfizer Inc, New York, USA). The following eight patients received intravitreal injections of bevacizumab $1.25 \mathrm{mg}$ in $0.05 \mathrm{~mL}$ prepared in a sterile compounding environment by the pharmacy service of our hospital. Injection procedures were identical for both therapies and included use of povidone iodine 5\%, a sterile drape and gloves, and an eyelid speculum. Follow-up visits for each patient occurred every 4 to 6 weeks for 6 months. Each visit included a complete ophthalmic 
examination, visual acuity assessment (ETDRS), and OCT. Reinjection of the initial medication occurred if there was evidence of intra- or subretinal fluid by OCT or an increase in RPE detachment.

Study endpoints were mean changes from baseline to month 6 in visual acuity (ETDRS and logMAR [logarithm of the minimum angle of resolution]), and in foveal thickness (OCT).

Informed consent was obtained. All applicable institutional and governmental regulations concerning the ethical use of human volunteers were followed during this research.

\section{Results}

Characteristics of the 15 patients were similar across treatment groups at baseline (Table 1); two patients who received pegaptanib and three who received bevacizumab had been treated previously with PDT with verteporfin. A mean of 3.7 (range 3-4) and 3.4 (range 2-5) injections of pegaptanib and bevacizumab were administered, respectively.

At baseline, mean visual acuity was lower and foveal thickness was greater in the pegaptanib treated patients (Table 2). Improvements in visual acuity measured by both ETDRS and $\log$ MAR and reductions in foveal thickness were seen in each treatment group between baseline and month 6 , but functional and anatomical changes were greater for all outcomes among patients treated with pegaptanib. The pattern of improvement varied by treatment (Figure 1). On average, pegaptanib-treated patients had

Table I Patient baseline characteristics ${ }^{\mathrm{a}}$

\begin{tabular}{|c|c|c|}
\hline Characteristic & $\begin{array}{l}\text { Pegaptanib } \\
0.3 \mathrm{mg} \mathrm{N}=7\end{array}$ & $\begin{array}{l}\text { Bevacizumab } \\
1.25 \mathrm{mg} \mathrm{N}=8\end{array}$ \\
\hline Mean age (years) & 74.5 & 73.3 \\
\hline \multicolumn{3}{|l|}{ Gender } \\
\hline Male & 4 & 4 \\
\hline Female & 3 & 4 \\
\hline \multicolumn{3}{|l|}{ Treated eye } \\
\hline Left & 4 & 5 \\
\hline Right & 3 & 3 \\
\hline \multicolumn{3}{|l|}{ Phakic/pseudophakic } \\
\hline Phakic & 5 & 6 \\
\hline Pseudophakic & 2 & 2 \\
\hline \multicolumn{3}{|l|}{ Previous treatment } \\
\hline None & 5 & 5 \\
\hline PDT with verteporfin & 2 & 3 \\
\hline
\end{tabular}

Note: ${ }^{a}$ Number of patients unless otherwise specified. Abbreviation: PDT, photodynamic therapy.
Table 2 Changes from baseline to month 6 in visual acuity and foveal thickness by treatment group, mean \pm standard deviation

\begin{tabular}{lcc}
\hline Outcome & $\begin{array}{c}\text { Pegaptanib } \\
\mathbf{0 . 3} \mathbf{~ m g ~ N}=\mathbf{7}\end{array}$ & $\begin{array}{c}\text { Bevacizumab } \\
\mathbf{1 . 2 5} \mathbf{~ m g ~ N ~ = ~ 8}\end{array}$ \\
\hline $\begin{array}{l}\text { Visual acuity, ETDRS letters } \\
\text { Baseline }\end{array}$ & $36.1 \pm 14.9$ & $49.5 \pm 11.5$ \\
Month 6 & $45.2 \pm 19.8$ & $56.7 \pm 10.5$ \\
Change, baseline to month 6 & $+9.1 \pm 25.3$ & $+7.2 \pm 12.3$ \\
Visual acuity, logMAR & & \\
Baseline & $1.00 \pm 0.31$ & $0.72 \pm 0.23$ \\
Month 6 & $0.80 \pm 0.40$ & $0.57 \pm 0.21$ \\
Change, baseline to & $-0.20 \pm 0.49$ & $-0.15 \pm 0.26$ \\
month 6 & & \\
Foveal thickness, $\mu \mathrm{mm}$ & & \\
Baseline & $470.4 \pm 140.8$ & $321.1 \pm 77.3$ \\
Month 6 & $382.2 \pm 99.4$ & $268.2 \pm 35.4$ \\
Change, baseline to month 6 & $-88.2 \pm 208.6$ & $-52.9 \pm 70.7$ \\
\hline
\end{tabular}

Abbreviations: ETDRS, Early Treatment Diabetic Retinopathy Study; logMAR, logarithm of the minimum angle of resolution.

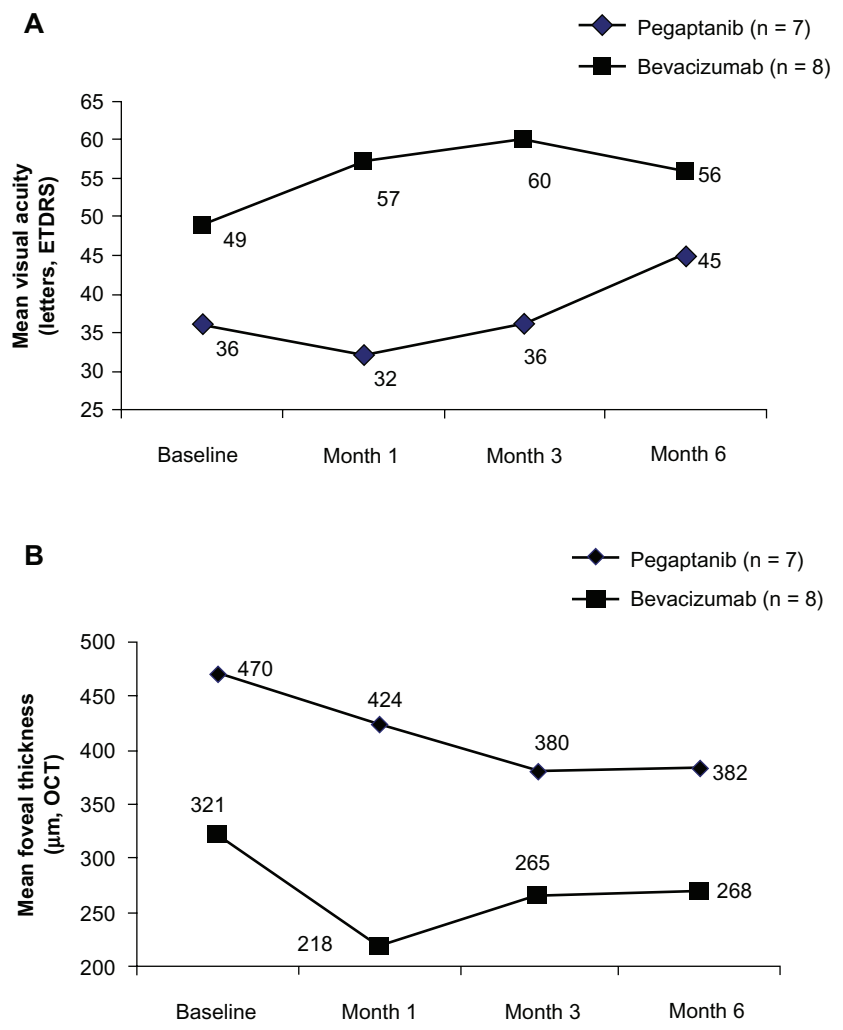

Figure I A) Mean visual acuity (VA; Early Treatment Diabetic Retinopathy Study [ETDRS] letters) at baseline and at months I, 3 and 6 in eyes receiving pegaptanib or bevacizumab. B) Mean foveal thickness $(\mu \mathrm{m})$ determined by optical coherence tomography (OCT) at baseline and at months I, 3, and 6 in eyes receiving pegaptanib or bevacizumab. 
slower but more sustained improvement in visual acuity and foveal thickness while those treated with bevacizumab demonstrated rapid improvement with a diminished effect over time.

Both agents were safe and well tolerated; neither ocular nor systemic complications were observed in any patient.

Illustrative cases of eyes treated with pegaptanib (Figures $2 \mathrm{~A}-\mathrm{C}$ and $3 \mathrm{~A}, \mathrm{~B}$ ) and bevacizumab (Figures 4A, B and $5 \mathrm{~A}, \mathrm{~B})$ are shown.

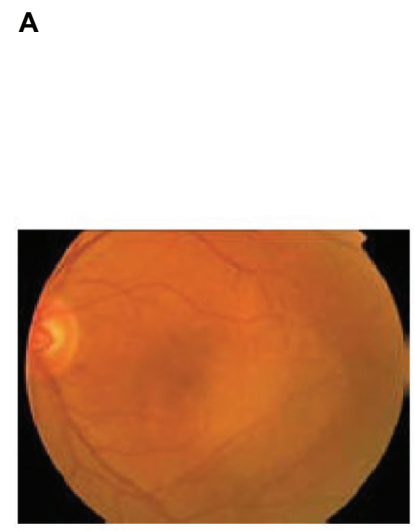

B
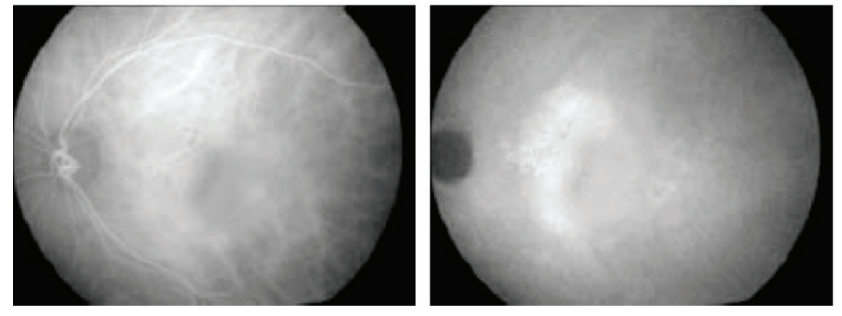

C

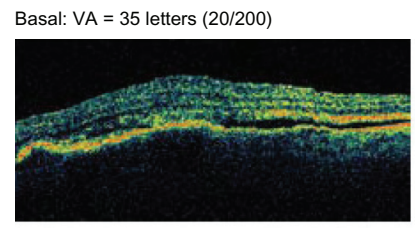

Month 3: VA $=53$ letters $(20 / 80)$
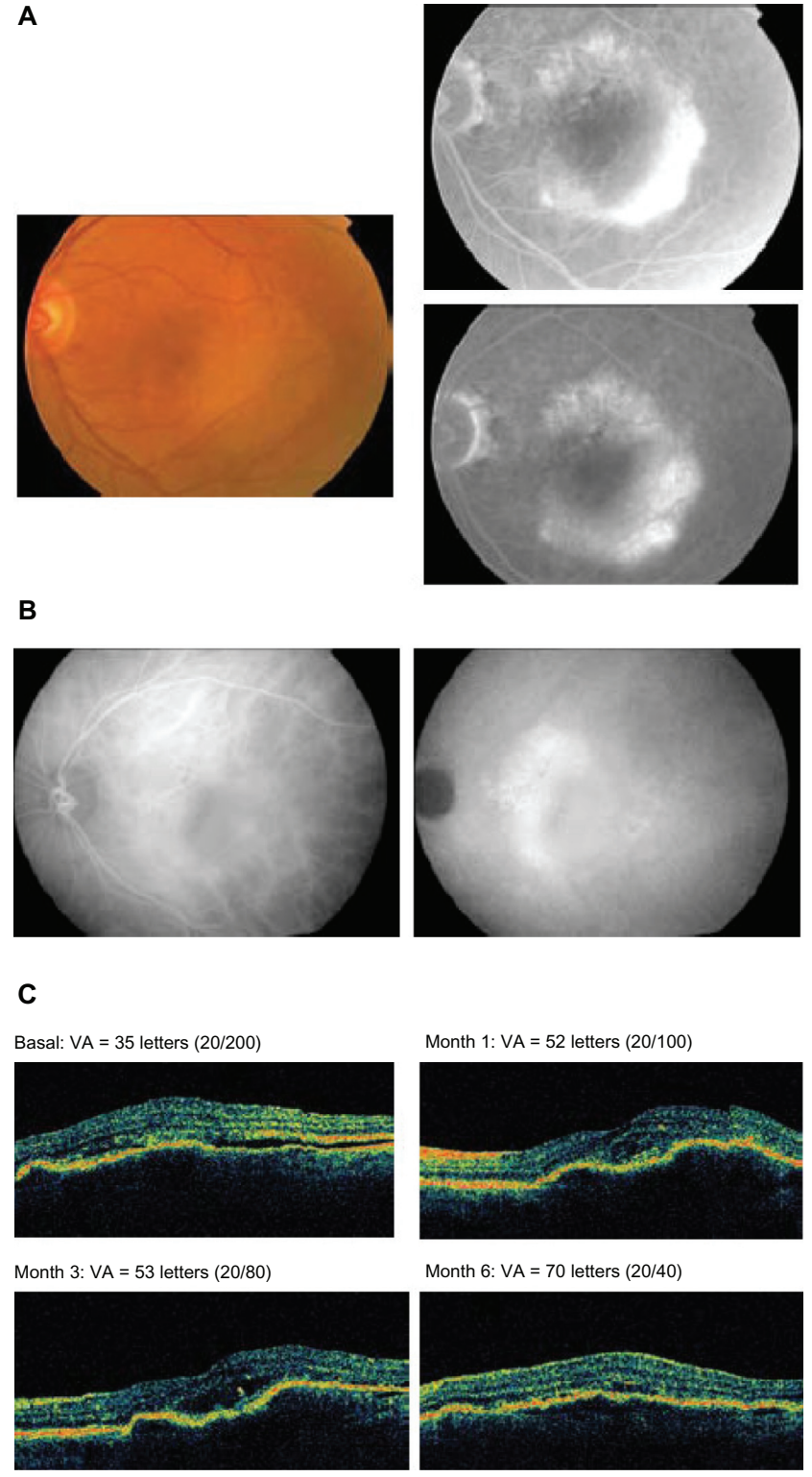

Month 6: VA $=70$ letters $(20 / 40)$

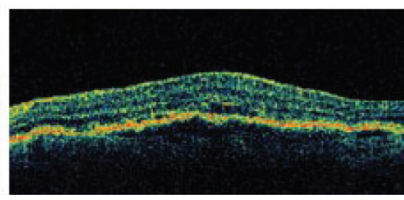

Figure 2 A 75-year-old female patient with previously untreated advanced age-related macular degeneration in the right eye received pegaptanib every 6 weeks for 3 injections. A) Fundus photograph at baseline (left panel) and fluorescein angiography (right panel). B) Indocyanine green angiography at baseline and 6 months. C) Optical coherence tomography images and visual acuity (VA; Early Treatment Diabetic Retinopathy Study [ETDRS] letters) at baseline and months I, 3, and 6.
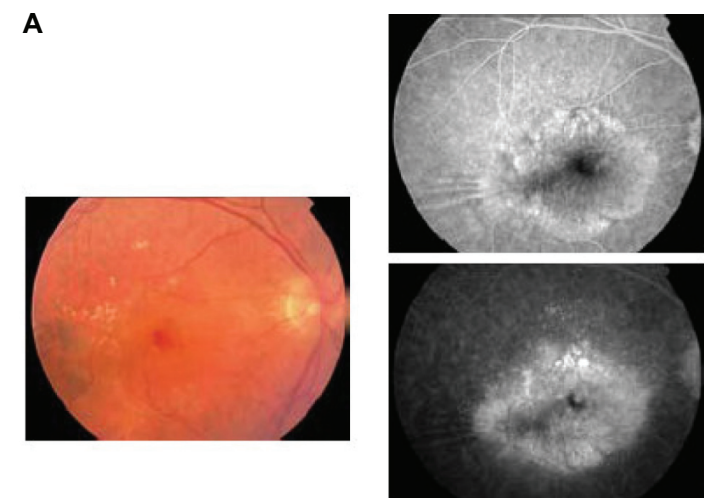

B

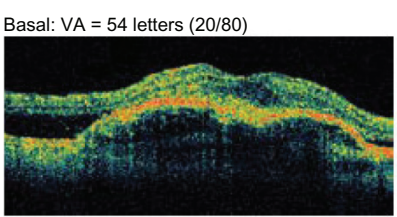

Month 3: VA $=44$ letters $(20 / 125)$

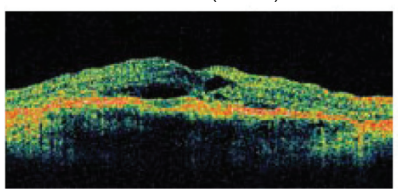

Month 1: VA $=45$ letters $(20 / 125)$

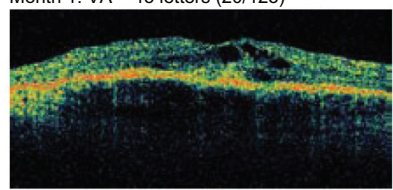

Month 6: VA $=42$ letters $(20 / 125)$

Figure 3 A 76-year-old male patient having a disciform scar in the left eye and no prior treatments received 4 injections of pegaptanib. A) Fundus photograph at baseline (left panel) and fluorescein angiography (right panel). B) Optical coherence tomography images and visual acuity (VA; Early Treatment Diabetic Retinopathy Study [ETDRS] letters) at baseline and months I, 3, and 6 .
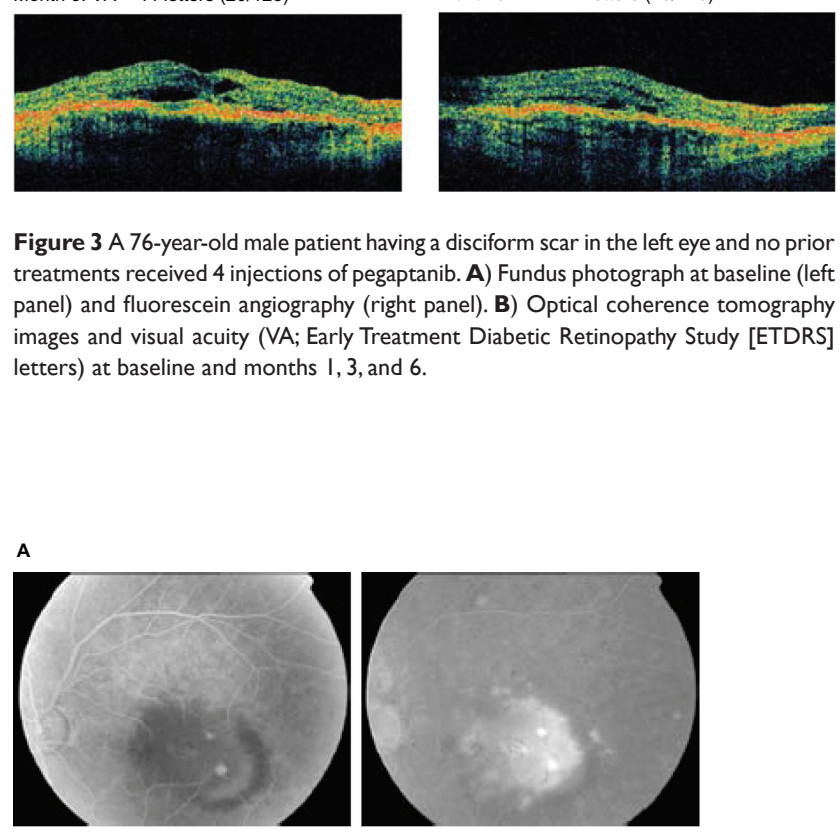

Basal: VA $=60$ letters $(20 / 63)$

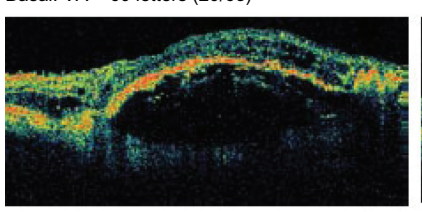

Month 1: VA $=35$ letters $(20 / 200)$

Month 3: VA $=45$ letters $(20 / 125)$
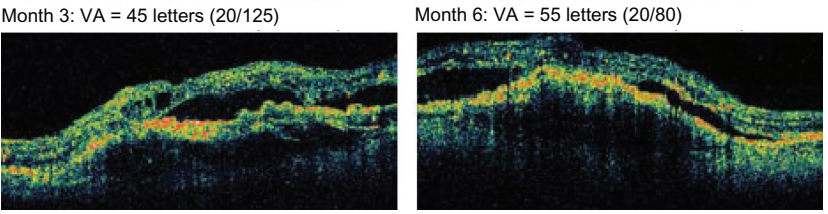

Figure 4 An 80-year-old male patient with a disciform scar in the right eye received prior photodynamic therapy with verteporfin and 3 injections of bevacizumab. A) Fluorescein angiography. B) Optical coherence tomography images and visual acuity (VA; Early Treatment Diabetic Retinopathy Study [ETDRS] letters) at baseline and months I, 3 , and 6 . 
A
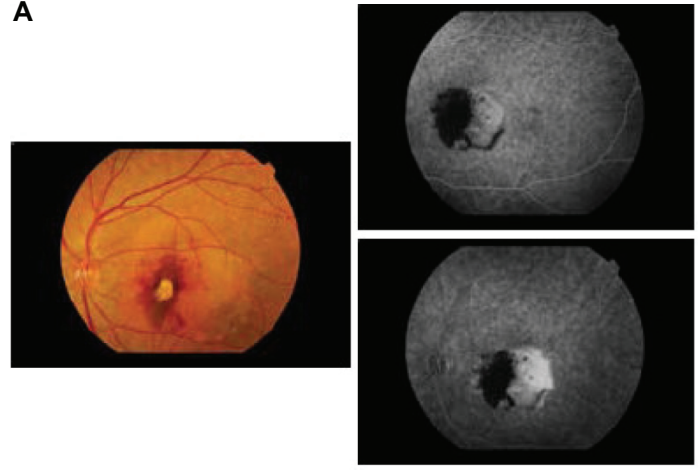

B

Basal: VA $=34$ letters $(20 / 250)$

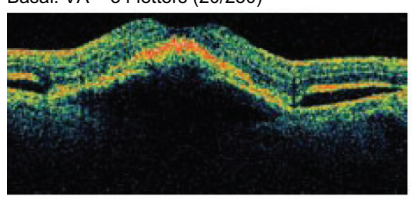

Month 3: VA $=58$ letters $(20 / 80)$

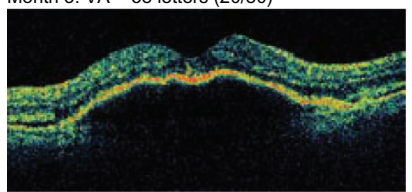

Month 1: VA $=59$ letters $(20 / 63)$

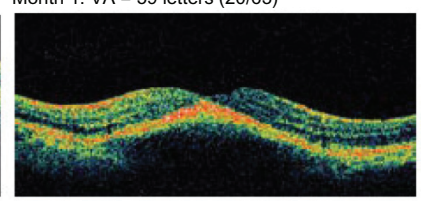

Month 6: VA $=68$ letters $(20 / 40)$

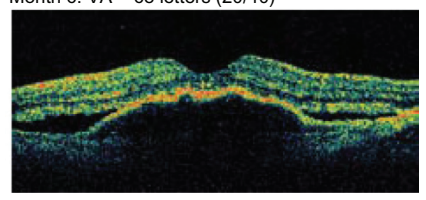

Figure 5 A 61 -year-old female patient with a normal right eye having received no prior treatments was administered 4 injections of bevacizumab. A) Fundus photograph at baseline (left panel) and fluorescein angiography (right panel). B) Optical coherence tomography images and visual acuity (VA; Early Treatment Diabetic Retinopathy Study [ETDRS] letters) at baseline and months I, 3, and 6.

\section{Discussion}

The principal finding in this pilot study is that both selective VEGF inhibition with pegaptanib and nonselective VEGF inhibition with bevacizumab provided similar anatomical and functional benefits in the treatment of PED, with no safety signals having emerged. These results are similar to those seen in another recent pilot study with bevacizumab, also directed against PED secondary to AMD. ${ }^{30}$ In the present report the two agents provided qualitatively similar benefits, while pegaptanib-treated patients showed somewhat greater improvements in terms of mean visual acuity and retinal thickness despite the overall poorer baseline condition. The difference in the number of injections administered between the treatment groups was less than $10 \%$, suggesting that undertreatment with bevacizumab was unlikely to be the cause. There also appeared to be a difference in the time courses of the responses to the two drugs, with patients receiving pegaptanib requiring a longer timeframe to achieve visual acuity improvements than bevacizumab, but one that was more sustained over the longer term. It is interesting that for both pegaptanib and bevacizumab the vision seemed to improve despite the fact that the PED size seems to have fluctuated over time.
While the data in the present study must be viewed as preliminary, they suggest that it may not be necessary to inhibit all VEGF isoforms for treatment of PED, in that selective inhibition of $\mathrm{VEGF}_{165}$ with pegaptanib produced comparable effects to bevacizumab. These findings are relevant to safety in that nonselective VEGF inhibition with ranibizumab was found be associated with a significantly higher incidence of nonocular hemorrhage compared to controls. ${ }^{31}$ In addition, early data from the Safety Assessment of Intravitreal Lucentis for AMD (SAILOR) trial examining ranibizumab safety has indicated a significantly increased risk of stroke for the $0.5 \mathrm{mg}$ versus $0.3 \mathrm{mg}$ dose, prompting a physician advisory letter from the manufacturer which can be found at: http://www.fda.gov/medwatch/safety/2007/Lucentis_DHCP_01-24-2007.pdf. Whether these risks apply to bevacizumab, which is also a nonselective VEGF antagonist, is not known, since its use has not been evaluated in large, properly controlled trials. ${ }^{29}$

Another issue of concern is the risk of RPE tears, a recognized complication of PED, in patients treated with anti-VEGF therapy. Chang and Sarraf ${ }^{32}$ have analyzed reports of RPE tears for all three anti-VEGF agents in the treatment of AMD and found that a pre-existing PED was a common feature. Similar conclusions have been reached in other retrospective studies with bevacizumab..$^{30,33,34} \mathrm{PED}$ is a predisposing factor for RPE tears even in untreated patients, and it remains to be determined whether anti-VEGF therapy accelerates the natural history of these cases, or contributes an additional risk that may require other adjustments in treatment regimens. ${ }^{32}$

The main limitation of this study is that it enrolled only a small number of patients. Other limitations included a lack of randomization and the relatively short duration of follow-up. Therefore, these findings require confirmation in a larger randomized study, which could also answer questions regarding the optimal dose, long-term efficacy and safety, and criteria for retreatment.

\section{Acknowledgments/disclosures}

The author reports no conflicts of interest in this work. This paper was supported with a grant from Pfizer Inc.

This study was presented as an oral presentation at the XI Vitreoretinal Spanish Society Congress ("XI Congreso de la Sociedad Española de Retina y Vítreo"), Madrid (16 February 2007).

\section{References}

1. Zayit-Soudry S, Moroz I, Loewenstein A. Retinal pigment epithelial detachment. Surv Ophthalmol. 2007;52:227-243. 
2. Thompson W. Classification of age-related macular degeneration. In: Alfaro DV, editor. Age-related macular degeneration: a comprehensive textbook. New York: Lippincott Williams \& Wilkins, 2005. p. 44-52.

3. Hartnett ME, Weiter JJ, Garsd A, Jalkh AE. Classification of retinal pigment epithelial detachments associated with drusen. Grafes Arch Clin Exp Ophthalmol. 1992;230:11-19.

4. Poliner LS, Olk RJ, Burgess D, Gordon ME. Natural history of retinal pigment epithelial detachments in age-related macular degeneration. Ophthalmology. 1986;93:543-551.

5. Gass JD. Serous retinal pigment epithelial detachment with a notch: a sign of occult choroidal neovascularization. Retina. 1984;4: 205-220.

6. Green WR, McDonnell PJ, Yeo JH. Pathologic features of senile macular degeneration. Ophthalmology. 1985;92:615-627.

7. Bird AC, Marshall J. Retinal pigment epithelial detachments in the elderly. Trans Ophthalmol Soc UK. 1986;105:674-682.

8. Bird AC. Doyne Lecture. Pathogenesis of retinal pigment epithelial detachment in the elderly; the relevance of Bruch's membrane change. Eye. 1991;5:1-12.

9. Singerman LJ, Stockfish JH. Natural history of subfoveal pigment epithelial detachments associated with subfoveal or unidentifiable choroidal neovascularization complicating age-related macular degeneration. Graefes Arch Clin Exp Ophthalmol. 1989;227:501-507.

10. Elman MJ, Fine SL, Murphy RP, Patz A, Auer C. The natural history of serous retinal pigment epithelium detachment in patients with agerelated macular degeneration. Ophthalmology. 1986;93:224-230.

11. Pauleikhoff D, Loffert D, Spital G, et al. Pigment epithelial detachment in the elderly. Clinical differentiation, natural course and pathogenetic implications. Graefes Arch Clin Exp Ophthalmol. 2002;240: $533-538$.

12. Teeters VW, Bird AC. The development of neovascularization of senile disciform macular degeneration. Am J Ophthalmol. 1973;76:1-18.

13. Slakter JS, Yannuzzi LA, Sorenson JA, Guyer DR, Ho AC, Orlock DA. A pilot study of indocyanine green videoangiography-guided laser photocoagulation of occult choroidal neovascularization in age-related macular degeneration. Arch Ophthalmol. 1994;112:465-472.

14. Moorfields Macular Study Group. Treatment of senile disciform macular degeneration: a single-blind randomised trial by argon laser photocoagulation. Br J Ophthalmol. 1982;66:745-753.

15. Baumal CR, Reichel E, Duker JS, Wong J, Puliafito CA. Indocyanine green hyperfluorescence associated with serous retinal pigment epithelial detachment in age-related macular degeneration. Ophthalmology. 1997;104:761-769.

16. Photodynamic therapy of subfoveal choroidal neovascularization in age-related macular degeneration with verteporfin: one-year results of 2 randomized clinical trials-TAP report. Treatment of age-related macular degeneration with photodynamic therapy (TAP) Study Group. Arch Ophthalmol. 1999;117:1329-1345.

17. Verteporfin therapy of subfoveal choroidal neovascularization in age-related macular degeneration: two-year results of a randomized clinical trial including lesions with occult with no classic choroidal neovascularization - verteporfin in photodynamic therapy report 2 . Am J Ophthalmol. 2001;131:541-560.
18. Pece A, Isola V, Vadala M, Calori G. Photodynamic therapy with verteporfin for choroidal neovascularization associated with retinal pigment epithelial detachment in age-related macular degeneration. Retina. 2007;27:342-348.

19. Axer-Siegel R, Ehrlich R, Rosenblatt I, et al. Photodynamic therapy for occult choroidal neovascularization with pigment epithelium detachment in age-related macular degeneration. Arch Ophthalmol. 2004;122:453-459.

20. Wygnanski-Jaffe T, Desatnik H, Alhalel A, et al. ICG angiographyguided photodynamic therapy for large pigment epithelial detachments in age-related macular degeneration. Ophthalmic Surg Lasers Imaging. 2006;37:358-363

21. Axer-Siegel R, Ehrlich R, Avisar I, et al. Combined photodynamic therapy and intravitreal triamcinolone acetonide injection for neovascular age-related macular degeneration with pigment epithelium detachment. Ophthalmic Surg Lasers Imaging. 2006;37:455-461.

22. Ferrara N. Vascular endothelial growth factor: basic science and clinical progress. Endocr Rev. 2004;25:581-611.

23. Senger DR, Connolly DT, Van de Water L, Feder J, Dvorak HF. Purification and NH2-terminal amino acid sequence of guinea pig tumor-secreted vascular permeability factor. Cancer Res. 1990;50:1774-1778.

24. Gragoudas ES, Adamis AP, Cunningham ET Jr, Feinsod M, Guyer DR. VEGF Inhibition Study in Ocular Neovascularization Clinical Trial Group. Pegaptanib for neovascular age-related macular degeneration. N Engl J Med. 2004;351:2805-2816.

25. Ng EW, Shima DT, Calias P, Cunningham ET Jr, Guyer DR, Adamis AP. Pegaptanib, a targeted anti-VEGF aptamer for ocular vascular disease. Nat Rev Drug Discov. 2006;5:123-132.

26. Brown DM, Kaiser PK, Michels M, et al. Ranibizumab versus verteporfin for neovascular age-related macular degeneration. $N$ Engl J Med. 2006;355:1432-1444.

27. Rosenfeld PJ, Brown DM, Heier JS, et al. Ranibizumab for neovascular age-related macular degeneration. $N$ Engl J Med. 2006;355: 1419-1431.

28. Ferrara N, Damico L, Shams N, Lowman H, Kim R. Development of ranibizumab, an anti-vascular endothelial growth factor antigen binding fragment, as therapy for neovascular age-related macular degeneration. Retina. 2006;26:859-870.

29. Lynch SS, Cheng CM. Bevacizumab for neovascular ocular diseases. Ann Pharmacother. 2007;41:614-625.

30. Chan CK, Meyer CH, Gross JG, et al. Retinal pigment epithelial tears after intravitreal bevacizumab injection for neovascular age-related macular degeneration. Retina. 2007;27:541-551.

31. Gillies MC, Wong TY. Ranibizumab for neovascular age-related macular degeneration. N Engl J Med. 2007;356:748-749.

32. Chang LK, Sarraf D. Tears of the retinal pigment epithelium: an old problem in a new era. Retina. 2007;27:523-534.

33. Kook D, Wolf A, Neubauer AS, et al. Retinal pigment epithelial tears after intravitreal injection of bevacizumab for AMD: Frequency and progress. [In German]. Ophthalmologe. 2008;105:158-164.

34. Ronan SM, Yoganathan P, Chien FY, et al. Retinal pigment epithelium tears after intravitreal injection of bevacizumab (Avastin) for neovascular age-related macular degeneration. Retina. 2007;27:535-540.
Clinical Ophthalmology

\section{Publish your work in this journal}

Clinical Ophthalmology is an international, peer-reviewed journal covering all subspecialties within ophthalmology. Key topics include: Optometry; Visual science; Pharmacology and drug therapy in eye diseases; Basic Sciences; Primary and Secondary eye care; Patient Safety and Quality of Care Improvements. This journal is indexed on Submit your manuscript here: http://www.dovepress.com/clinical-ophthalmology-journal

\section{Dovepress}

PubMed Central and CAS, and is the official journal of The Society of Clinical Ophthalmology (SCO). The manuscript management system is completely online and includes a very quick and fair peer-review system, which is all easy to use. Visit http://www.dovepress.com/ testimonials.php to read real quotes from published authors. 